\title{
Geographic distribution of authors in The Indexer, 1988-2007
}

\section{Catherine Sassen}

Catherine Sassen reports on her study of the geographic location of authors contributing to volumes I 6 through 25 of The Indexer. Although the majority of authors were from the United Kingdom, there was a steady increase in the participation of authors from other countries throughout the 20-year period. Authors from outside the United Kingdom made up 14.86 percent of all authors in 1988-9I, and grew to 38.27 percent in 2004-07. Geographic diversity was found to be greater among authors of articles than among authors of editorials, letters, or reviews.

\section{Introduction}

Throughout the history of The Indexer, its subtitle has indicated a geographic context. The subtitle of the first issue was 'Journal of the Society of Indexers'. The subtitle changed in 1972 to 'Journal of the Society of Indexers and of the American Society of Indexers'. In 1977 it changed to 'Journal of the Society of Indexers, the American Society of Indexers, and the Australian Society of Indexers'. In 1979 it changed again to 'Journal of the Society of Indexers and of the affiliated American \& Australian \& Canadian Societies'.

The geographic context of The Indexer widened even more when its subtitle was changed to 'The International Journal of Indexing' in volume 21, no. 4, published in October 1999. This issue contained the text of the international agreement between the indexing societies of Great Britain and Ireland, the United States, Canada, Australia and Southern Africa (Halliday, 1999). In the following issue, published in April 2000, the China Society of Indexers was added to the list of affiliated indexing societies. More international diversity was evidenced in the April 2005 issue in which the 'Australian and New Zealand Society of Indexers' replaced the 'Australian Society of Indexers' on the list. In the October 2006 issue, the list expanded again with the addition of the German Network of Indexers and the Netherlands Indexing Network.

The relationship between The Indexer and the affiliated indexing societies has been explained by its editor, Maureen MacGlashan (2007, 402):

The British Society of Indexers retains responsibility for publication of The Indexer and for the appointment of the editor, but it does so on behalf of all the affiliated indexing societies who are entitled to a say in policy, and whose members figure increasingly as contributors, as guest editors and as members of the production team.

This study was undertaken to determine whether the expanding geographic context of The Indexer was reflected in its authorship from 1988 through 2007. Of primary interest was the geographic location of the authors whose articles, editorials, letters and reviews appeared in The Indexer during this 20-year period.

\section{Methodology}

Volumes 16 through 25 of The Indexer, published from 1988 through 2007, were analyzed. Authorship information was gathered through personal examination of each issue.

'Authorship' was defined as the person or persons who were identified as the writers of articles, editorials, letters, and reviews. Using the methodology of Olsgaard and Olsgaard (1980), each instance of authorship was considered as a separate case. Therefore, a contribution written through the collaboration of two authors was counted as two authorship cases. Multiple contributions written by the same author were counted separately. For example, if an author contributed one article in 1988 and another in 2003, each article was considered as a separate instance of authorship.

The byline and biographical information accompanying each contribution were analyzed to identify the geographic location of each author. 'Geographic location' was defined as the country in which the author worked, not the national origin of the author. If the byline listed more than one author, information about each author was recorded.

If information about the geographic location of the author was not available in the byline or in the accompanying biographical information, the name was searched in other sources. Some names were found in lists of editorial board members of The Indexer. Other names were found in the lists of indexing society officers, published in each issue of The Indexer. Other searches were performed in Library Literature and Information Science Full Text and in Library and Information Science Abstracts. If citations to other articles by the same author were found, those articles were examined to find information about the geographic location of the author. If author information was not found in those sources, the websites of national indexing societies were searched. In the remaining cases, the editor of The Indexer was asked for information.

Perhaps the most difficult part of an authorship study is determining what to include. This study included articles, editorials, letters to the editor, and reviews. The category of 
'articles' included historical and descriptive papers, quantitative research, position papers, conference presentations, case studies, biographies, centrepieces, bibliographies and indexes. (Indexes are usually excluded from authorship studies, but they were included here as an acknowledgment of their importance and of the effort that they involve.) Excluded were brief news items, announcements of upcoming events, summaries of conferences, brief reports of awards, and reports on articles in earlier issues of The Indexer. Unsigned contributions were excluded, as well as contributions signed only by initials which were not the editor's. Also excluded were features compiled with the assistance of many contributors, such as 'Indexes reviewed' and reports from national indexing societies.

\section{Overall geographic distribution of authors}

Authors from United Kingdom made up a majority of the authors of all types of contributions. They ranged from 85.14 percent of all authors in 1988-1991 to 61.73 percent of all authors in 2004-07. The participation of authors outside the United Kingdom increased steadily over time, accounting for 14.86 percent of all authors in 1988-91, and growing to 38.27 percent in $2004-07$.

A total of 21 countries are represented by authors in The Indexer from 1988 through 2007. Following the United Kingdom, the geographic areas most often represented are the United States, Canada, and Australia. The geographic distribution of authors of all types of contributions is summarized in Table 1 and Chart 1.

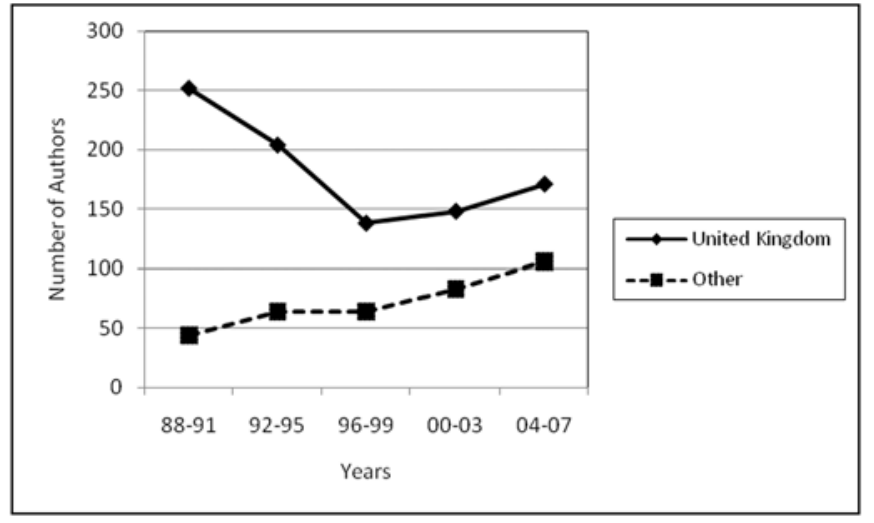

Chart I Number of authors by geographic location per four-year period

\section{Editorials}

A trend of greater geographic diversity over time was found among authors of editorials. Authors from the United Kingdom made up the majority of all authors during the 20year period studied. Authors from outside the United Kingdom grew from 0 percent in $1988-91$ to 45.45 percent in 1996-99, decreasing to 41.67 percent in 2000-03 and declining further to 20 percent in 2004-07.

The distribution of authors of editorials is illustrated in Table 2 and Chart 2. The number of authors is not the same in each time period because some journal issues contained more than one editorial, and some editorials were written by more than one author.

The concept of 'issue editors' was introduced in volume

Table I Geographic distribution of all authors

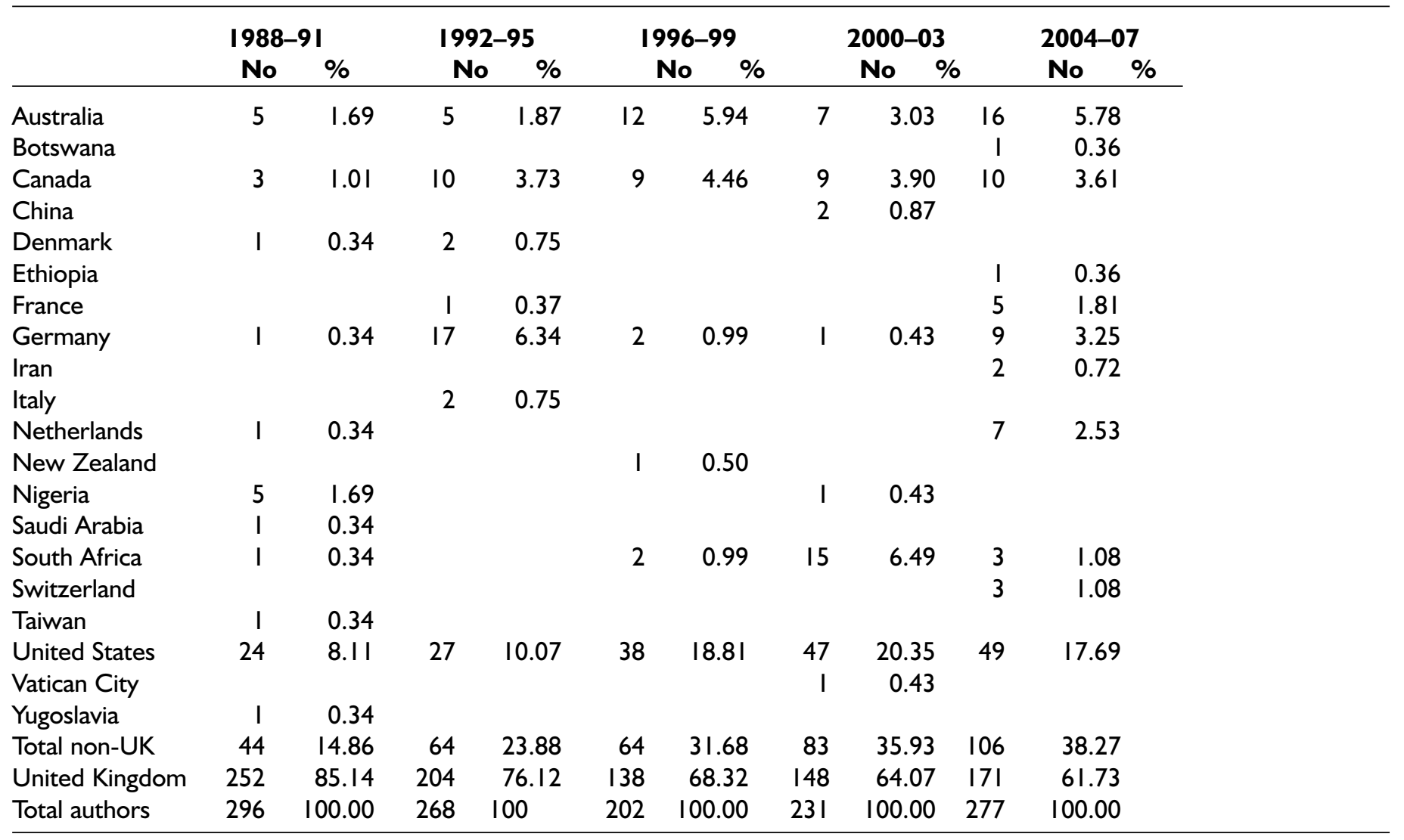


Table 2 Geographic distribution of authors of editorials

\begin{tabular}{|c|c|c|c|c|c|c|c|c|c|c|}
\hline & \multicolumn{2}{|c|}{ | 988-9| } & \multicolumn{2}{|c|}{ | 992-95 } & \multicolumn{2}{|c|}{ 1996-99 } & \multicolumn{2}{|c|}{ 2000-03 } & \multicolumn{2}{|c|}{ 2004-07 } \\
\hline & No & $\%$ & No & $\%$ & No & $\%$ & No & $\%$ & No & $\%$ \\
\hline Australia & & & & & 1 & 9.09 & 1 & 8.33 & & \\
\hline Canada & & & & & & & I & 8.33 & & \\
\hline Germany & & & & & & & & & I & 6.67 \\
\hline Netherlands & & & & & & & & & 1 & 6.67 \\
\hline Southern Africa & & & & & & & I & 8.33 & & \\
\hline United States & & & 2 & 25.00 & 4 & 36.36 & 2 & 16.67 & 1 & 6.67 \\
\hline Total non-UK & 0 & 0.00 & 2 & 25.00 & 5 & 45.45 & 5 & 41.67 & 3 & 20.00 \\
\hline United Kingdom & 8 & 100.00 & 6 & 75.00 & 6 & 54.55 & 7 & 58.33 & 12 & 80.00 \\
\hline Total authors & 8 & 100.00 & 8 & 100.00 & II & 100.00 & 12 & 100.00 & 15 & 100.00 \\
\hline
\end{tabular}

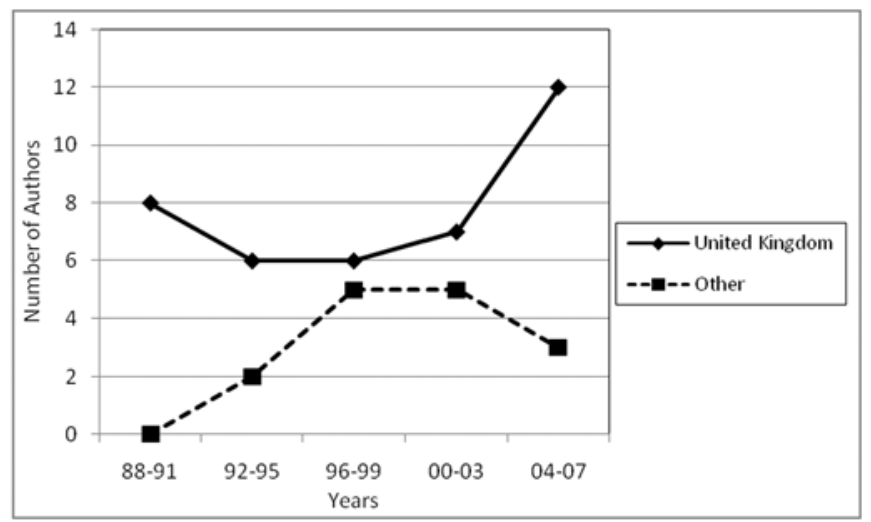

Chart 2 Number of authors of editorials by geographic location per four-year period

21, no. 4 of The Indexer, published in October 1999. This was the first issue to bear the subtitle of 'The International Journal of Indexing'. The executive editor stated:

From the April 2000 issue (vol. 22, no. 1) we are also introducing the concept of Issue Editors. For each issue an individual or group, who may be members of the Society of Indexers or of one of the affiliated Societies in the international group, will be appointed by the Execu- tive Editor to commission articles, but without responsibility for production. We hope that this new arrangement will further increase the international interest and appeal of the journal.

(Shuttleworth 1999)

Before the concept of issue editors was introduced in October 1999, only the United Kingdom, the United States and Australia were represented by the authors of editorials. After October 1999, the geographic diversity of authors of editorials increased. In subsequent issues, The Indexer included editorials from eight members of affiliated indexing societies outside the United Kingdom, including Australia (volume 22, no. 3), South Africa (volume 23 no. 2), Canada (volume 23, no. 3), the Netherlands (volume 25, no. 2) Germany (volume 25, no. 2) and the United States (volume 22 , no. 1 , volume 23 , no. 1 and volume 24 , no. 2 ). (The China Society of Indexers has accepted an invitation to guest edit the October 2009 issue.)

\section{Letters to the editor}

Greater international participation was found over time among the authors of letters to the editor. Authors from the United Kingdom made up the majority of all letter writers

Table 3 Geographic distribution of authors of letters

\begin{tabular}{|c|c|c|c|c|c|c|c|c|c|c|}
\hline \multirow[b]{3}{*}{ Australia } & \multicolumn{2}{|c|}{ |988-9| } & \multicolumn{2}{|c|}{ 1992-95 } & \multicolumn{2}{|c|}{$1996-99$} & \multicolumn{2}{|c|}{ 2000-03 } & \multicolumn{2}{|c|}{ 2004-07 } \\
\hline & No & $\%$ & No & $\%$ & No & $\%$ & No & $\%$ & No & $\%$ \\
\hline & 3 & 6.82 & & & 3 & 17.65 & & & I & 7.14 \\
\hline Canada & I & 2.27 & & & & & & & & \\
\hline Denmark & I & 2.27 & I & 2.56 & & & & & & \\
\hline France & & & I & 2.56 & & & & & & \\
\hline Germany & & & & & & & & & 2 & 14.29 \\
\hline Italy & & & I & 2.56 & & & & & & \\
\hline Netherlands & I & 2.27 & & & & & & & & \\
\hline New Zealand & & & & & I & 5.88 & & & & \\
\hline South Africa & I & 2.27 & & & & & & & & \\
\hline United States & 6 & 13.64 & II & 28.21 & 5 & 29.41 & 4 & 33.33 & 3 & 21.43 \\
\hline Total non-UK & 13 & 29.55 & 14 & 35.90 & 9 & 52.94 & 4 & 33.33 & 6 & 42.86 \\
\hline United Kingdom & 31 & 70.45 & 25 & 64.10 & 8 & 47.06 & 8 & 66.67 & 8 & 57.14 \\
\hline Total authors & 44 & 100.00 & 39 & 100.00 & 17 & 100.00 & 12 & 100.00 & 14 & 100.00 \\
\hline
\end{tabular}




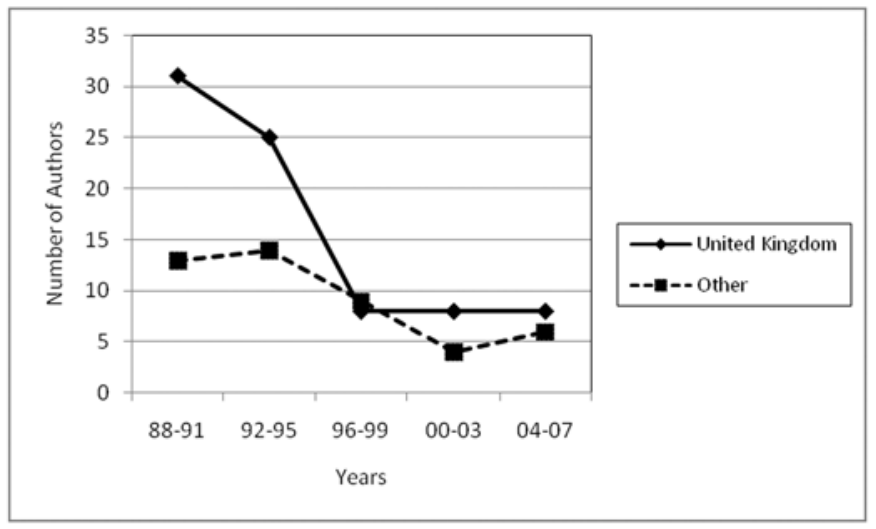

Chart 3 Number of authors of letters by geographic location per four-year period

during all periods studied, except for 1996-99 when they made up 47.06 percent of all authors. Authors from outside the United Kingdom represented 29.55 percent of all letter writers in 1988-91, increasing to a high of 52.94 percent in 1996-99, declining to 33.33 percent in 2000-03 and then increasing to 42.86 percent in 2004-07.

Letters to the editor have come from a total of 11 countries. The countries represented most often besides the United Kingdom are the United States and Australia. The geographic distribution of the authors of letters appearing in The Indexer is summarized in Table 3 and Chart 3.

\section{Reviews}

The authors of book and software reviews became more geographically diverse during the period studied. Authors from the United Kingdom accounted for 99.28 percent of all review authors in 1988-91, and continued to make up the majority of all authors during subsequent years. Authors from outside the United Kingdom made steady increases beginning in the year 2000. In 2000-03, they made up 22.86 percent of all review authors, and in 2004-07 they increased to 34.34 percent.

Seven countries are represented by authors of reviews. After the United Kingdom, the country represented most often was the United States. The marked increase in US authors, beginning in the year 2000, is undoubtedly a result

Table 4 Geographic distribution of authors of reviews

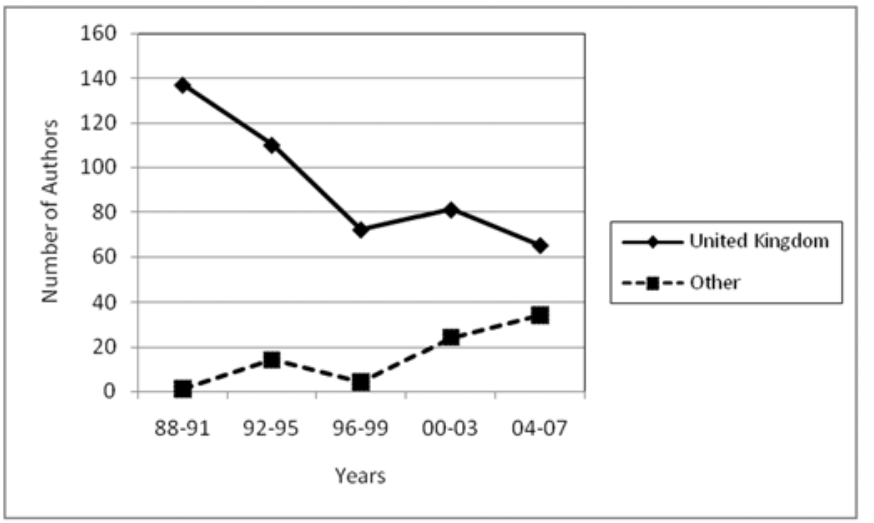

Chart 4 Number of authors of reviews by geographic location per four-year period

of the work of the North American reviews editor, first introduced in volume 22, no. 1, published in April 2000. The geographic distribution of authors of book and software reviews is presented in Table 4 and Chart 4.

\section{Articles}

A trend of greater international participation over time was found among the authors of articles. Authors from countries outside the United Kingdom made up 28.3 percent of all article authors in 1988-91. This group of authors grew to constitute 49.02 percent of all authors in 2000-03 and then

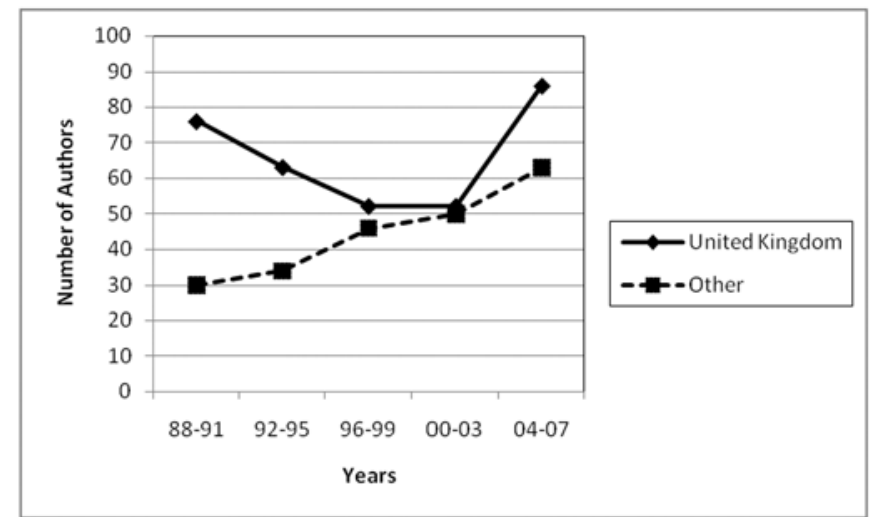

Chart 5 Number of authors of articles by geographic location per four-year period

\begin{tabular}{|c|c|c|c|c|c|c|c|c|c|c|}
\hline & \multicolumn{2}{|c|}{ |988-9| } & \multicolumn{2}{|c|}{ 1992-95 } & \multicolumn{2}{|c|}{ 1996-99 } & \multicolumn{2}{|c|}{ 2000-03 } & \multicolumn{2}{|c|}{ 2004-07 } \\
\hline & No & $\%$ & No & $\%$ & No & $\%$ & No & $\%$ & No & $\%$ \\
\hline Australia & & & I & 0.81 & & & & & 4 & 4.04 \\
\hline Canada & & & & & & & $\mathrm{I}$ & 0.95 & 4 & 4.04 \\
\hline Germany & & & 13 & 10.48 & 2 & 2.63 & $\mathrm{I}$ & 0.95 & & \\
\hline Netherlands & & & & & & & & & 2 & 2.02 \\
\hline South Africa & & & & & & & & & 2 & 2.02 \\
\hline United States & $\mathrm{I}$ & 0.72 & & & 2 & 2.63 & 22 & 20.95 & 22 & 22.22 \\
\hline Total non-UK & I & 0.72 & 14 & 11.29 & 4 & 5.26 & 24 & 22.86 & 34 & 34.34 \\
\hline United Kingdom & 137 & 99.28 & 110 & 88.71 & 72 & 94.74 & 81 & 77.14 & 65 & 65.66 \\
\hline Total authors & 138 & 100.00 & 124 & 100.00 & 76 & 100.00 & 105 & 100.00 & 99 & 100.00 \\
\hline
\end{tabular}


Table 5 Geographic distribution of authors of articles

\begin{tabular}{|c|c|c|c|c|c|c|c|c|c|c|}
\hline \multirow[b]{3}{*}{ Australia } & \multicolumn{2}{|c|}{ | 988-9| } & \multicolumn{2}{|c|}{ |992-95 } & \multicolumn{2}{|c|}{ | 996-99 } & \multicolumn{2}{|c|}{$2000-03$} & \multicolumn{2}{|c|}{ 2004-07 } \\
\hline & No & $\%$ & No & $\%$ & No & $\%$ & No & $\%$ & No & $\%$ \\
\hline & 2 & 1.89 & 4 & 4.12 & 8 & 8.16 & 6 & 5.88 & II & 7.38 \\
\hline Botswana & & & & & & & & & I & 0.67 \\
\hline Canada & 2 & 1.89 & 10 & 10.31 & 9 & 9.18 & 7 & 6.86 & 6 & 4.03 \\
\hline China & & & & & & & 2 & 1.96 & & \\
\hline Denmark & & & I & 1.03 & & & & & & \\
\hline Ethiopia & & & & & & & & & $\mathrm{I}$ & 0.67 \\
\hline France & & & & & & & & & 5 & 3.36 \\
\hline Germany & $\mathrm{I}$ & 0.94 & 4 & 4.12 & & & & & 6 & 4.03 \\
\hline Iran & & & & & & & & & 2 & I.34 \\
\hline Italy & & & I & 1.03 & & & & & & \\
\hline Netherlands & & & & & & & & & 4 & 2.68 \\
\hline Nigeria & 5 & 4.72 & & & & & I & 0.98 & & \\
\hline Saudi Arabia & I & 0.94 & & & & & & & & \\
\hline South Africa & & & & & 2 & 2.04 & 14 & 13.73 & $\mathrm{I}$ & 0.67 \\
\hline Switzerland & & & & & & & & & 3 & 2.01 \\
\hline Taiwan & I & 0.94 & & & & & & & & \\
\hline United States & 17 & 16.04 & 14 & 14.43 & 27 & 27.55 & 19 & 18.63 & 23 & 15.44 \\
\hline Vatican City & & & & & & & I & 0.98 & & \\
\hline Yugoslavia & I & 0.94 & & & & & & & & \\
\hline Total non-UK & 30 & 28.30 & 34 & 35.05 & 46 & 46.94 & 50 & 49.02 & 63 & 42.28 \\
\hline United Kingdom & 76 & 71.70 & 63 & 64.95 & 52 & 53.06 & 52 & 50.98 & 86 & 57.72 \\
\hline Total authors & 106 & 100.00 & 97 & 100.00 & 98 & 100.00 & 102 & 100.00 & 149 & 100.00 \\
\hline
\end{tabular}

decreased to 42.28 percent in 2004-07. The geographic distribution of the authors of articles is summarized in Table 5 and Chart 5.

The geographic diversity of the authors of articles is greater than the diversity of authors of editorials, letters, or reviews. There are 20 countries represented by authors of articles, as summarized in Table 5. Every country represented by an affiliated indexing society is included. After the United Kingdom, the countries represented most often are the United States, Canada, and Australia.

\section{Conclusion}

The editor has repeatedly made clear her determination to make this a truly international journal, building on the efforts of her predecessors. This analysis of the statistics shows that she is having some success. The fact that the China Society of Indexers will be guest-editing the September 2009 issue is a further step in this direction. It is this ongoing internationalization of the journal which offers the best hope of its celebrating the centenary of its foundation in 2058 .

\section{Bibliography}

Halliday, J. (1999) International agreement. Indexer 21(4), 154.

MacGlashan, M. (2007) The Indexer: past, present and future. Information Wissenschaft \& Praxis 58(8), 402-6.

Olsgaard, J. N. and Olsgaard, J. K. (1980) Authorship in five library periodicals. College \& Research Libraries 41(1), 49-53.

Shuttleworth, C. (1999) Editorial changes. Indexer 21(4), 153.
Catherine Sassen is principal catalog librarian at the University of North Texas, Denton, Texas.

Email: Catherine.Sassencunt.edu

\section{indexing specialists}

Our team of experts have many years' experience in undertaking and designing effective indexes

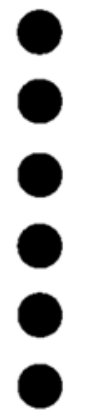

Books, journals, manuals

Multi-volume works

From 100,000 to 100 lines

Unfamiliar subjects

Design of style and layout

Short deadlines met

Phone $+44(0) 1273738299 \quad$ Fax $+44(0) 1273323309$ email richardr@indexing.co.uk website www.indexing.co.uk

\section{INDEXING SPECIALISTS (UK) LTD \\ Regent House, Hove Street, Hove \\ East Sussex BN3 2DW, UK}


Copyright of Indexer is the property of Society of Indexers and its content may not be copied or emailed to multiple sites or posted to a listserv without the copyright holder's express written permission. However, users may print, download, or email articles for individual use. 